\title{
Structured communication intervention to reduce anxiety of family members waiting for relatives undergoing surgical procedures
}

Follow this and additional works at: https://www.journal.acorn.org.au/jpn

Part of the Health Services Administration Commons, Health Services Research Commons, Perioperative, Operating Room and Surgical Nursing Commons, and the Surgery Commons

\section{(c) (7)}

This work is licensed under a Creative Commons Attribution 4.0 License.

\section{Recommended Citation}

Kynoch, Kathryn; Crowe, Linda; McArdle, Annie; Munday, Judy; Cabilan, CJ; and Hines, Sonia (2017) "Structured communication intervention to reduce anxiety of family members waiting for relatives undergoing surgical procedures," Journal of Perioperative Nursing: Vol. 30 : Iss. 1 , Article 3. Available at: https://doi.org/10.26550/2209-1092.1013

https://www.journal.acorn.org.au/jpn/vol30/iss1/3

This Article is brought to you for free and open access by Journal of Perioperative Nursing. It has been accepted for inclusion in Journal of Perioperative Nursing by an authorized editor of Journal of Perioperative Nursing. 


\section{Author \\ Kate Kynoch \\ PhD, MN, RN \\ Mater Health Services / Queensland Centre for Evidence Based Nursing and Midwifery (A Joanna Briggs Institute Centre of Excellence), Brisbane, Queensland}

\section{Linda Crowe}

PhD, MMid, BN, RN, RM

Mater Health Services / Queensland

Centre for Evidence Based Nursing and

Midwifery (A Joanna Briggs Institute

Centre of Excellence), Brisbane,

Queensland

\section{Annie McArdle}

Masters Adv Prac (Health Care Research), $\mathrm{RN}, \mathrm{RM}, \mathrm{M} \& \mathrm{CH}$

Mater Health Services, Brisbane,

Queensland

\section{Judy Munday}

DipEd(Nurs), RN

Mater Health Services, Brisbane, Queensland

\section{CJ Cabilan}

BN, RN

Mater Health Services / Queensland

Centre for Evidence Based Nursing and

Midwifery (A Joanna Briggs Institute

Centre of Excellence), Brisbane,

Queensland

\section{Sonia Hines}

MAppSci (Research), GradDipEd (Adult \&

Tertiary), BN, RN

Mater Health Services / Queensland

Centre for Evidence Based Nursing and

Midwifery (A Joanna Briggs Institute

Centre of Excellence), Brisbane,

Queensland

\section{Corresponding author}

Dr Kate Kynoch

Director - Nursing Research Centre

Director - Queensland Centre for

Evidence Based Nursing and Midwifery:

A Joanna Briggs Institute Centre of

Excellence

Mater Health Services Ltd

Aubigny Place, Raymond Terrace, South

Brisbane, Qld, 4101

t: (07) 31638181

e: Kathryn.Kynoch@mater.org.au

\title{
Structured communication intervention to reduce anxiety of family members waiting for relatives undergoing surgical procedures
}

\begin{abstract}
Perioperative nurses recognise that family members experience increased levels of anxiety during the wait for a relative undergoing a surgical procedure. It is often during this time that little or no meaningful communication occurs between family members and health professionals. It has been suggested that a structured information intervention has the potential to increase communication between families and health care professionals as well as decrease family members' anxiety.
\end{abstract}

The aim of this study was to establish the effect of a structured communication program on anxiety of family members' awaiting relatives undergoing surgical procedures. A quasi-experimental design was used with a sample of 129 family members of patients undergoing surgical procedures in a tertiary hospital in Brisbane, Australia. Consecutive sampling was used to recruit family members for the control group and the intervention group. The intervention group received a structured intervention which included an information card as well as an in-person nursing report. The control group received usual care. A demographic data collection form and the State-Trait Anxiety Inventory were used to collect data.

Results from the study suggest that the structured communication intervention reduced family anxiety; however, results were not statistically significant. An important finding of this study was that only one relative in the control group received information during the perioperative time period indicating a need to improve communication between families and staff. It was concluded that more nursing interventions designed to reduce family members' anxiety during the operative waiting period are needed.

\section{Keywords}

family, perioperative nurse, anxiety, communication, information

\section{Introduction}

Waiting by patients and their families is often seen by health care professionals as a normal, routine part of the surgery process ${ }^{1-3}$. For the family however, the experience of waiting can be stressful causing significant negative impacts in both immediately and in the long term ${ }^{2,4}$. Feelings of anxiety are described frequently in the literature?.

Information sharing as an intervention to reduce anxiety in the perioperative unit has been investigated in studies involving patients and to a lesser extent families. 
Munday et al. in their systematic review examined the effectiveness of information-sharing interventions to reduce anxiety of families waiting for surgical patients undergoing elective surgical procedure ${ }^{5}$. Although the review only found three studies that met the inclusion criteria, the findings suggested that an in-person intervention to update families on the patient's status could be effective in reducing anxiety.

At the time of the study, there was no recognised protocol, guideline or policy to guide perioperative nurses in their interactions with family members in the immediate post-operative period at the study hospital. Consequently, little or no information was provided to families during this time. Therefore, we investigated the effects of an informational intervention on the anxiety levels of family members in this important time.

\section{Aim}

To investigate the effectiveness of a structured communication intervention to reduce the anxiety of family members waiting for their relatives who are undergoing an elective surgical procedure.

The term 'family' for the purposes of this study was defined as 'a selfdefined group of individuals who derive support from each other' ${ }^{6}$.

\section{Objectives}

The objectives of this study were to

- determine if the intervention reduces family's anxiety

- determine if perioperative communication is improved

- explore the influences of family socio-demographic characteristics on anxiety levels.

Our hypothesis therefore was: families of patients admitted to the operating theatres for an elective surgical procedure who received the structured communication intervention will have lower levels of anxiety in comparison to families receiving usual care.

\section{Literature review}

The experience of waiting and the effects it has on families engaging in the health care system have been documented by numerous authors ${ }^{1,7}$. Waiting for news of their loved one can cause family members to experience anxiety, depression, agitation and sleep disturbances? Anxiety, in particular, can have a number of impacts on the wellbeing of the family as well as the patient. Anxiety can interfere with family members' ability to receive and understand information as well as their ability to sustain family functioning ${ }^{4,8}$. Furthermore, anxiety can interfere with the family's coping strategies and ability to provide support to the patient ${ }^{3,4}$. Unmitigated family anxiety can also result in hypervigilance and disruptive behaviour by family members that impacts on the nursing care provided ${ }^{4}$. Anxiety amongst families during surgical waiting episodes is often characterised by uncertainty about outcome and duration of surgery as well as the separation of patient and family during the procedure ${ }^{4}$. Health care professionals need to be mindful that, whether routine or urgent, surgical admissions are not everyday occurrences and are often major life events for both patients and families ${ }^{3}$. Interventions to reduce family anxiety are important to perioperative staff, families and patients.

It is evident from the literature that perioperative nurses recognise the increased levels of anxiety family members experience during the time a relative is undergoing a surgical procedure ${ }^{5}$. However, the literature also highlights it is often during this time period that little or no meaningful communication occurs between family members and health professionals. Interactions between health professionals and families have been described as 'fragmented' during this period' ${ }^{9}$. A lack of information or explanation about routines also contributes to a perception of an overall lack of support for waiting families 2,10 . A study into the perioperative needs of family members found informational needs to be their highest priority ${ }^{11,12}$.

Organised methods of communication may help to ensure that information provided to families is consistent, pertinent and effective. As technology develops, the options for different methods of updating families are likely to grow. To date, in-person updates $^{13,14}$, telephone updates ${ }^{15}$, pager communication ${ }^{16}$ and the use of Twitter $^{17}$ have been documented. Both face-to-face interventions ${ }^{13-15}$ and communication with families via an information card $^{18}$ (detailing expected durations of surgery and waiting procedures) $)^{13,15}$ appear to show some promising results in reducing family anxiety. Research in this area is still needed as available studies are either limited, older or have methodological flaws 5 .

Our study was based on the combination of two interventions: in-person updates as well as communication via an information card. These two interventions have both been studied in previous research separately but have not been used in combination. Studies using an in-person update intervention have demonstrated a reduction of anxiety but this reduction did not reach statistical significance ${ }^{13-15}$. On the other hand, the study that used an information card showed a decreased level of anxiety but a validated instrument was not used to measure anxiety ${ }^{18}$. 
The content of information updates in our study was based on previous studies and included general procedural information as well as an update when patients reached the recovery phase of care in the Post Anaesthesia Care Unit (PACU) 10,15,19. Explanations of delays have also been found to be reassuring so they were also included in the intervention ${ }^{20}$.

\section{Methods}

\section{Study design and setting}

A quasi-experimental design was used, using a non-randomised convenience sample, with data collected in two distinct sequential phases (control and intervention), to reduce the risk of cross-exposure between groups. The study site was the operating theatres in a large tertiary hospital in southeast Queensland. Ethical approval was obtained from the hospital's Human Research Ethics Committee.

\section{Population and sample size}

Prior to study recruitment, the sample size was determined on a medium effect size as reported in two previous studies investigating family member anxiety during the perioperative period ${ }^{13,15}$. This resulted in a requirement for 128 participants (64 in each arm) to detect a significant difference between the two groups with a type 1 error of 0.05 and power of 0.0821 .

Adult family members (preferably those closest to the patient), who were able to read and write English, and able to be present with the patient on the day of surgery, both on admission and at the completion of the surgery, were invited to participate.

Data collection took place from March to July in 2014, during elective surgery hours, typically 7.00 am to 4.30 pm on Mondays to Fridays.

\section{Intervention}

After a detailed literature search ${ }^{5}$, a structured communication intervention was developed and comprised:

1. an information card given to families prior to the patient's scheduled procedure. The card included

- a general outline of surgical process

- the likely duration of surgery (approximate)

- information about waiting areas and amenities.

2. an in-person update to families when the patient arrived in the PACU, including the nursing plan for the patient.

\section{Data collection tools}

The State-Trait Anxiety Inventory (STAI)22 was used to collect data for this study. The STAI is widely used and measures state and trait anxiety, both in clinical practice settings and in scientific research. There are 40 items - 20 assessing for trait anxiety and 20 assessing state anxiety. The state score indicates anxiety about an event and the trait score indicates anxiety as a personality characteristic. All items are scored on a four-point Likert scale, where greater anxiety is indicated with a higher score. Good reliability and validity has previously been shown in many clinical areas including the surgical setting ${ }^{23-25}$ and in measuring family anxiety during the perioperative period 14,15,20.

Family members participating in the study also completed a demographic data collection form. Participants in both the intervention and control group were required to complete the questionnaires after the patient had arrived in the PACU.

\section{Data collection procedure}

On the day of surgery, eligible family members were invited to participate in the study. Family members were given time to read the study information sheet, ask questions and further clarify information about the study, prior to giving written consent. Participants were allocated a Study ID number and any identifying information was available only to the research assistant. The initial 64 participants recruited to the study were allocated to the control group and, thereafter, the second 64 participants were allocated to the intervention group. Allocation to the intervention group commenced after the data collection period of the control group was completed to prevent the aforementioned risk of cross-exposure between the two groups. Data collection for the study continued until the desired sample size was attained.

The control group received usual care, although they were requested to stay within the hospital for the duration of the patient's surgery. The family member then completed the demographic form and STAI after the patient was admitted to the PACU. Apart from the recruitment and data collection processes, the study's research assistant provided no further information to participants about their family member's condition than is usual.

The intervention group participants were then enrolled. Recruitment, consent and data collection was identical to the process employed for the control group. However, the intervention group were provided with an information card prior to the surgery that detailed the expected waiting time, which ward the patient was expected to be transferred to from the PACU (if known at this time) and amenities in the surrounding area. After the 
patient was transferred to the PACU, the research assistant visited family members in the waiting area and provided them with an update about their relative's progress. Participants then completed the demographic form and the STAI.

Recruitment and data collection was conducted by the study's research assistant who was an experienced perioperative nurse and trained in the specific recruitment and intervention strategies of this present study.

\section{Data analysis}

SPSS Version 15 was used for the data analysis. Descriptive statistics describe the sample characteristics with means and standard deviations summarising the continuous data. Categorical data was summarised using frequencies and percentages. At the bivariate level, unpaired t-tests were used for comparison between two groups for continuous data. For comparisons between two groups of categorical data, chi-squared testing was used. To explore the relationship between two continuous variables, Pearson's product-moment correlation was used. Statistical significance was set at 0.05 .

\section{Results}

During the data collection period 129 relatives of surgical patients consented to participate in the study. Sixty-six participants were recruited into the control (usual care) group and 63 were recruited into the intervention group. The two groups were similar with the mean age being 50 years of age for both groups. There were no significant differences between ethnic background, occupation, education or relationship, with most relatives being spouses or partners. As well, the trait anxiety score for each group

\begin{tabular}{|c|c|c|}
\hline Variable & $\begin{array}{c}\text { Control } \\
\text { group } \\
n=66\end{array}$ & $\begin{array}{c}\text { Intervention } \\
\text { group } \\
n=63^{*}\end{array}$ \\
\hline Age - mean (SD) & $50.1(13.8)$ & $50.0(14.7)$ \\
\hline $\begin{array}{l}\text { Gender - n (\%) } \\
\text { Male } \\
\text { Female }\end{array}$ & $\begin{array}{l}34(51.5) \\
32(48.5)\end{array}$ & $\begin{array}{l}23(36.5) \\
39(61.9)\end{array}$ \\
\hline $\begin{array}{l}\text { Relationship }-\mathrm{n}(\%) \\
\text { Spouse/partner } \\
\text { Parent } \\
\text { Child } \\
\text { Sibling } \\
\text { Extended family member } \\
\text { Friend } \\
\text { Missing / not specified }\end{array}$ & $\begin{array}{l}36(54.5) \\
11(16.7) \\
14(21.2) \\
2(3.0) \\
2(3.0) \\
1(1.5) \\
0\end{array}$ & $\begin{array}{l}39(61.9) \\
14(22.2) \\
5(7.9) \\
1(1.6) \\
0 \\
3(4.8) \\
1(1.6)\end{array}$ \\
\hline $\begin{array}{l}\text { Cultural background - n (\%) } \\
\text { Oceanian } \\
\text { North-west European } \\
\text { North-east Asian } \\
\text { Southern and eastern European } \\
\text { South-east Asian } \\
\text { Southern and central Asia } \\
\text { Missing / not specified }\end{array}$ & $\begin{array}{l}46(69.7) \\
7(10.6) \\
4(6.1) \\
1(1.5) \\
4(6.1) \\
2(3.0) \\
2(3.0)\end{array}$ & $\begin{array}{l}48(76.2) \\
8(12.7) \\
0 \\
1(1.6) \\
1(1.6) \\
3(4.8) \\
2(3.2)\end{array}$ \\
\hline $\begin{array}{l}\text { Highest education level } \\
\text { High school } \\
\text { Tertiary } \\
\text { Postgraduate } \\
\text { Other } \\
\text { Missing / not specified }\end{array}$ & $\begin{array}{l}30(45.5) \\
24(36.4) \\
6(9.1) \\
6(9.1) \\
0\end{array}$ & $\begin{array}{l}28(44.4) \\
20(31.7) \\
10(15.9) \\
4(6.3) \\
1(1.6)\end{array}$ \\
\hline $\begin{array}{l}\text { Employment status - n (\%) } \\
\text { Unemployed } \\
\text { Self-employed } \\
\text { Casual } \\
\text { Part-time } \\
\text { Full-time } \\
\text { Retired } \\
\text { Missing / not specified }\end{array}$ & $\begin{array}{l}10(15.2) \\
7(3.0) \\
3(4.5) \\
5(7.6) \\
32(48.5) \\
9(13.6) \\
0\end{array}$ & $\begin{array}{l}8(12.7) \\
3(4.8) \\
7(11.1) \\
9(14.3) \\
25(39.7) \\
10(15.9) \\
1(1.6)\end{array}$ \\
\hline $\begin{array}{l}\text { Occupation - } n(\%) \\
\text { Managers } \\
\text { Professionals } \\
\text { Technicians and trades workers } \\
\text { Community and personal service } \\
\text { Clerical and administrative workers } \\
\text { Sales workers } \\
\text { Machinery operators and drivers } \\
\text { Labourers } \\
\text { Not working / retired } \\
\text { Missing / not specified }\end{array}$ & $\begin{array}{l}7(10.6) \\
15(22.7) \\
7(10.6) \\
8(12.1) \\
5(7.6) \\
0 \\
3(4.5) \\
4(6.1) \\
17(25.8) \\
0\end{array}$ & $\begin{array}{l}1(1.6) \\
15(23.8) \\
2(3.2) \\
8(12.7) \\
5(7.9) \\
1(1.6) \\
6(9.5) \\
7(11.1) \\
16(25.4) \\
2(3.2)\end{array}$ \\
\hline Trait anxiety - mean (SD) & $34.3(8.8)$ & $33.1(8.9)$ \\
\hline
\end{tabular}

Table 1: Demographic characteristics

* Data on gender for one participant in the intervention group was missing. 
was similar, indicating comparable anxiety characteristics (see Table 1).

State anxiety scores were considered to ascertain if the intervention affected the anxiety state of participants relating to the current situation (a family member's surgical treatment). Supporting our hypothesis, state anxiety scores for the intervention group were lower than the control group with mean scores of $35.03(S D=11.07)$ and 36.85 $(S D=12.51)$ respectively, although this difference was not shown to be statistically significant ( $p=.573)$.

Communicating with family members about the care and condition of their loved one was an integral aspect of this study's intervention and all participants $(n=63,100 \%)$ in the intervention group received an update in the immediate postoperative period. Members of the control group were asked if they received any information about the patient and only one (1.5\%) did gain some information about their relative in the immediate post-operative period.

Age was the only socio-demographic characteristic that was found to alter state anxiety levels. There was a small, negative correlation between the two variables $(r=-.20, n=128$, $p=.02$ ) with higher levels of state anxiety associated with the younger age of family members.

\section{Discussion}

The aim of the present study was to determine if a targeted communication intervention would decrease anxiety levels of family members of patients undergoing elective surgery. The results indicate that family members who received information about their relative in the immediate post-operative period had lower levels of anxiety than family members who received routine care. However, as the trait anxiety scores were also lower in the intervention group, this finding may simply be the result of overall lower baseline anxiety in the intervention group. The finding that there was a small, negative correlation between age and state anxiety is supported by previous research which has suggested that younger people are more likely to worry ${ }^{26}$.

An important finding of this study was the lack of communication during the immediate postoperative period between health care professionals and families in the usual care (control) group. This is consistent with reports from other health care settings in which communication between perioperative staff and family members is ad hoc at best ${ }^{9}$. While there are many interventions that are able to engage and support families, the intervention in this present study is ideal because it is delivered as the patient's recovery begins and the intervention is in person. Studies have shown that families prefer to be given information that is specific to their relative and for the information to be delivered in person, particularly if the surgery is taking longer than expected $^{27}$.

Blum et al. ${ }^{19}$ and Cunningham et al. ${ }^{9}$ found that in the immediate post-operative period even snippets or fragments of information given to relatives about their family member decreases their anxiety and increases their satisfaction. These findings are consistent with the family-centred care approach which advocates that open communication and timely information exchange is critical to supporting patients and families ${ }^{10}$. A family-centred approach to perioperative care can be useful for nurses and have more farreaching benefits than merely in the immediate post-operative period ${ }^{28}$. Carmody suggests that being informed and supported equips families with the capacity to cope with what may be a situational crisis or even a life crisis, if the surgery is life threatening (e.g. cardiac surgery) or lifesaving (e.g. excision of a tumour) ${ }^{11}$. The study intervention presented participants with up-todate information about their loved one, as well as the opportunity to be comforted and supported by nurses.

Anecdotally, in this current study some perioperative staff members were uninterested and even uncooperative in the implementation of this intervention. This behaviour is not surprising as any practice change can be difficult to implement into the clinical setting. To ensure success, others implementing this intervention, or a similar intervention, would need to consider barriers to practice change. These barriers may include but are not restricted to: lack of space in the unit to ensure patient confidentiality and privacy ${ }^{29}$, lack of staff resources (e.g. shortage of workforce and heavy workloads) ${ }^{30-32}$, and lack of workplace policies and practices to support family involvement ${ }^{32}$. A dedicated role in the perioperative area that is devoted to providing families with regular up-to-date information may overcome some of the barriers outlined above. However, to enable significant practice change within the intraoperative environment, Baker $^{33}$ and White ${ }^{34}$ emphasised the importance of committed leadership which includes financial support, transparency and staff participation.

\section{Significance of this research}

This study adds to the body of evidence required to implement practice changes in the perioperative unit. Although further research is required, it raises the awareness of the informational needs of families and the anxiety experienced by families. 


\section{Limitations of the study}

This study was limited by the fact that it was conducted in one site and therefore the results may not be extrapolated to the Australian population. Family satisfaction was not explored and this is an important factor in the care of patients and their families. A larger study may find statistically significant differences between the two groups.

\section{Recommendations for future research}

This current study has suggested that providing information to families of surgical patients in the immediate post-operative period is valuable. Further studies will be required to establish whether a statistical significant difference in anxiety levels can be demonstrated between the two groups. As implementation of this intervention would require change in current practice, studies should also be conducted on the cost-effectiveness and feasibility of the intervention to ensure benefit to patients, families and the organisation.

Further research may also focus on other methods of communicating with families such as a dedicated nursing role, SMS messaging, tweeting or even a dedicated phone application in this area of nursing practice.

\section{Recommendations for clinical practice}

This current study highlights the need for a different approach to how perioperative nurses communicate information to families. Due to the lack of statistically significant results the implementation of this particular structured communication intervention cannot be recommended for clinical practice. However, this study did highlight the lack of communication between perioperative staff and patients' families. There is evidence that families have informational needs while waiting during their loved one's surgery. Perioperative units need to look at how they might meet these needs.

\section{Conclusion}

This project has contributed to the knowledge base surrounding family anxiety, and the results suggest that information given in a timely manner to relatives of surgical patients during the intraoperative period will decrease anxiety levels and increase communication. There may need to be a change in attitudes and approaches to family members in order to implement practice change in the perioperative environment and therefore improve the holistic health of surgical patients and their families. This requires organisations to acknowledge the important role families play in the care and recovery of patients in the acute health care system.

\section{References}

1. Rittenmeyer L, Huffman D, Godfrey C. The experience of patients, families and/ or significant others of waiting when engaging with the healthcare system: A qualitative systematic review. JBI Database of Systematic Reviews and Implementation Reports 2014;12(8):193-258.

2. Trimm D, Sanford J. The process of family waiting during surgery. J Fam Nurs 2010;16(4):852-861.

3. Patelarou A, Melidoniotis E, Sgouraki M, Karatzi $M$, Souvatzis $X$. The effect of visiting surgical patients in the postanesthesia care unit on family members' anxiety: A prospective quasi-experimental study. J Perianesth Nurs 2014;29(3):221-229.

4. Mojdeh S, Zamani M, Kooshki AM, Jafari $\mathrm{N}$. Effect of watching a movie on family members' anxiety level during their relatives' surgery. Iran J Nurs Midwifery Res 2013;18(4):329.

5. Munday J, Kynoch K, Hines S. The effectiveness of information sharing interventions to reduce anxiety in families waiting for surgical patients undergoing an elective surgical procedure: A systematic review. JBI Database of Systematic Reviews and Implementation Reports 2014;12(3):234273

6. Majasaari H, Sarajärvi A, Koskinen H, Autere S, Paavilainen E. Patients' perceptions of emotional support and information provided to family members. AORN J 2005;81(5):1030-1039.

7. Sadeghi T, Nayeri ND, Abbaszadeh A. The waiting process: A grounded theory study of families' experiences of waiting for patients during surgery. J Res Nurs 2015;20(5):372-382.

8. Hamester L, Souza ENd, Cielo C, Moraes MA, Pellanda LC. Effectiveness of a nursing intervention in decreasing the anxiety levels of family members of patients undergoing cardiac surgery: A randomized clinical trial. Rev Lat Am Enfermagem 2016;24.

9. Cunningham M, Hanson-Heath C, Agre P. A perioperative nurse liaison program. CNS intervention for cancer patients and their families. J Nurs Care Qual 2003;18(1):16-21.

10. Stefan KA. The nurse liaison in perioperative services: A family-centered approach. AORN J 2010;92(2):150-157.

11. Carmody S, Hickey P, Bookbinder M. Perioperative needs of families. AORN J 1991;54(3):561-567.

12. Lerman $Y$, Kara I, Porat N. Nurse liaison: The bridge between the perioperative department and patient accompaniers. AORN J 2011;94(4):385-392.

13. Trecartin K, Carroll D. Nursing interventions for family members waiting during cardiac procedures. Clin Nurs Res 2011;20(3):263-275.

14. Leske JS. Effects of intraoperative progress reports on anxiety of elective surgical patients' family members. Clin Nurs Res 1992;1(3):266-277.

15. Leske J. Intraoperative progress reports decrease family members' anxiety. AORN J. 1996;64(3):424-436.

16. Topp R, Walsh E, Sanford E. Can providing paging devices relieve waiting room anxiety? AORN J 1998;67(4):852־-861.

17. Twitter opens a door to lowa operating room [Internet]. Douglas, Isle Of Man, UK: Omicron Technology Limited; 2 September 2009 [cited 2016 Aug 20]. Available from: phys.org/news171121774.html.

18. Muldoon M, Cheng D, Vish N, DeJong S, Adams J. Implementation of an informational card to reduce family members' anxiety. AORN J 2011;94(3):246-253.

19. Blum E, Burns S. Perioperative communication and family members' perceived level of anxiety and satisfaction. ORNAC J 2013;31(3):14-16.

20. MacDonald K, Latimer M, Drisdelle N. Determining the impact of a surgical liaison 
nurse role in the paediatric operating room. ORNAC J 2006;24(1):7-36.

21. Cohen J. Quantitative methods in psychology. A power primer. Psychol Bull 1992;112(1):155-159.

22. Spielberger C. State-Trait Anxiety Inventory. John Wiley \& Sons, Inc; 2010.

23. Acar H, Cuvas Ö, Ceyhan A, Dikmen B. Acupuncture on Yintang point decreases preoperative anxiety. J Altern Complement Med 2013;19(5):420-424.

24. Candido M, Andreatini R, Zielak J, de Souza J, Losso E. Assessment of anxiety in patients who undergo surgical procedures for tooth implants: A prospective study. J Oral Maxillofac Surg 2015;19(3):253-258.

25. Ikeda N, Tomizawa R, Moriya R, Yamanaka J, Suzuki H, Eguchi $H$, et al. Perioperative anxiety, pain, and salivary amylase in patients undergoing pancreatic surgery. IJPS 2015;7(2):206-213.

26. Gonçalves D, Byrne G. Who worries most? Worry prevalence and patterns across the lifespan. Int J Geriat Psychiatry 2013;28(1):4149.

27. Dexter F, Epstein RH. Reducing family members' anxiety while waiting on the day of surgery: systematic review of studies and implications of HIPAA health information privacy rules. J Clin Anesth 2001;13(7):478-481.

28. Chorney JM, Kain ZN. Family-centered pediatric perioperative care. Anesthesiology 2010;112(3):751-755.

29. Wolff J. Family matters in healthcare delivery. JAMA 2012;308(15):1592-1530.
30. Leino Kilpi H, Gröndahl W, Katajisto 」, Nurminen M, Suhonen R. Participation of family members and quality of patient care - the perspective of adult surgical patients. J Clin Nurs 2016;25(15-16):2242-2250.

31. Chan EA, Jones A, Wong K. The relationships between communication, care and time are intertwined: A narrative inquiry exploring the impact of time on registered nurses' work. J Adv Nurs 2013;69(9):2020-2029.

32. Groves W. Professional practice skills for nurses. Nurs Stand 2014;29(1):51-59.

33. Baker J. Innovation: The foundation for change. AORN J 2014;99(2):187-190.

34. White A. Implementing change in the perioperative setting. AORN 2014;99(2):C7-C8. 